This is the peer reviewed version of the following article:

Panadero, S., Martín, R., \& Vázquez, J. J. (2018). Suicide attempts and stressful life events among homeless people in Madrid (Spain). Journal of Community \& Applied Social Psychology, 28(4), 200-212,

which has been published in final form at:

https://doi.org/10.1002/casp.2351

This article may be used for non-commercial purposes in accordance with Wiley Terms and Conditions for Use of Self-Archived Versions. 
Accepted version of the article:

Panadero, S., Martín, R., \& Vázquez, J. J. (2018). Suicide attempts and stressful life events among homeless people in Madrid (Spain). Journal of Community \& Applied Social Psychology, 28(4), 200-212. DOI: doi.org/10.1002/casp.2351

Copyright: (C) Wiley Periodicals, Inc.

\section{SUICIDE ATTEMPTS AND STRESSFUL LIFE EVENTS AMONG HOMELESS PEOPLE IN MADRID (SPAIN)}

$$
\text { Sonia Panadero }{ }^{1} \text {, Rosa Martín }{ }^{2} \text { and José Juan Vázquez }{ }^{2}
$$

1. Clinical Psychology Department, School of Psychology, Complutense University of Madrid, 28223, Madrid, Spain.

2. Social Psychology Department. Alcala University, 28801, Alcala de Henares. Madrid, Spain.

Corresponding author: José Juan Vázquez, Ph.D., Área de Psicología Social, Universidad de Alcalá, Aulario María de Guzmán, C/San Cirilo, s/n. 28801 Alcalá de Henares, Madrid, Spain. Email: ji.vazquez@uah.es

Funding statement: This research was supported by the "Agencia Estatal de Investigación" of the "Ministerio de Economía, Industria y Competitividad" of Spain under Grant "FEM201675317-R".

Conflicts of interest: None of the authors have any conflict of interest. 


\begin{abstract}
The article describes a study carried out with a representative sample of homeless people in Madrid (Spain; $\mathrm{N}=188$ ). This study aims to corroborate the relationship identified in the literature between stressful life events and suicidal behaviour in a group in a situation of social exclusion, to assess the differences in the number and characteristics of stressful life events experienced by homeless people who are attempters and non-attempters, and to identify which combination of stressful life events enables discrimination for suicide attempts among homeless people. The results show that $30 \%$ of homeless people in Madrid had attempted suicide, and $57.9 \%$ of them had done so for the first time when they were homeless. The interviewees are shown to have experienced a large amount of stressful life events, with substantially more stressors experienced by the homeless people who tried to commit suicide, during both their childhood and adolescence and throughout their life. Finally, we found that the combination of 7 stressful life events provided the best possible discrimination between homeless attempters and non-attempters
\end{abstract}

Keywords: homeless people, stresful life events, suicidal attempts. 


\section{Introduction}

Mortality among homeless people in developed countries is much higher than among the general population (Barrow, Herman, Cordova, \& Struening, 1999; Hwang, 2000; Nusselder et al., 2013). Among the causes of this high mortality, deaths due to suicide have rarely been considered, although the data available on suicide attempts suggest that the actual suicide rate among this group may be remarkably high (Barak, Cohen, \& Aizenberg, 2004; Barrow et al., 1999; Hwang, 2000). Various studies that have examined suicide attempts among homeless adults in developed countries have found very high percentages of homeless people who have attempted suicide, albeit with important variations: e.g. 48\% in Montreal, Canada (Lamontagne, Garceau-Durand, Elie \& Blais, 1988); 34.1\% in Toronto, Canada (Eynan et al., 2002); 22\% in Los Angeles (USA) (Gelberg, Linn \& Leake, 1988); and 22\% among hostel users in St. Louis (Smith, North, \& Spitznagel, 1993). In a large sample of 2,974 homeless people in the USA, Dietz (2011) noted that 6\% reported that they had attempted suicide in the previous year.

The scientific literature establishes the existence of an important relationship between the risk of suicide and suffering from multiple stressful life events (SLE). These experiences play a key role in the individual's life and frequently lead to significant changes for the person involved (Vázquez, Panadero \& Martín, 2015). The Stress-Diathesis Model of Suicidal Behaviour (Van Heeringen, 2012; Van Heeringen \& Mann, 2014) posits that suicide is the result of an interaction between state-dependent (environmental) stressors and a trait-like diathesis or susceptibility to suicidal behaviour. Within the framework of this model, the experiencing of many and severe SLE during childhood and throughout life can have a very negative effect on people with a trait-like diathesis -a predisposition or persistent vulnerability which can be described in psychological or biological terms- or susceptibility to suicidal behaviour. Lopez-Castroman, Olié \& Courtet (2014) point out that environmental insults during pregnancy, childhood, or adolescence induce neurodevelopmental changes that increase the vulnerability for suicidal behaviour in later life.

Various studies have shown that both suicides and suicide attempts are to a large extent precipitated by different SLE (Cheng, Chen, Chen, \& Jenkins, 2000; Heikkinen et al., 1997; Paykel, Prusoff \& Myers, 1975; Vázquez, Panadero, \& Rincón, 2007; 2010). Osvath et al. (2004) for the general population, Beautrais et al. (1997) and Cooper et al. (2002) for young people, and Guillén, Panadero, Rivas, and Vázquez (2015) for populations in situations of social exclusion or difficulty found that interviewees who had attempted suicide had in overall terms suffered from significantly more SLE than the non-attempters. Suffering from many SLE, especially if these take place during the first years of life and if they are related to the family environment, seems to be an important vulnerability factor for suicide attempts in the future (Vázquez et al., 2015; Vázquez et al., 2007; 2010).

Suffering from SLE is particularly prevalent among the groups in situations of poverty and social exclusion, both during childhood and adolescence and throughout their lives (Guillén et al., 2015; Leonori et al., 2000; Vázquez et al. 2015; Vázquez et al., 2007, 2010). Various studies show that a history of physical and/or sexual abuse during childhood (Beautrais, Joyce, \& Mulder, 1996; Brown, Cohen, Johnson, \& Smailes, 1999; Pompili et al., 2011; Vázquez et al., 2010), and impaired or neglectful parenting (Beautrais et al., 1996; Brent et al., 1993; Johnson et al., 2002) are particularly powerful SLE when they are experienced in the first years of life, and are associated with a major risk of suicidal behaviour in adult life.

Among homeless people, suffering from physical or sexual violence during childhood has been linked to subsequent drug use and suicidal behaviour (Dietz, 2010). The most important of the main issues studied in relation to suicidal behaviour among the homeless are 
psychoactive substance abuse (Rodell, Benda, \& Rodell, 2003), mental health problems (Benda, 2005) and psychiatric comorbidity with substance abuse As Serafini et al. (2012) point out, the association between psychoactive substance use, mental illness and suicidal behaviour has frequently been reported, although the exact nature of this link is underinvestigated. In a study specifically on suicidal ideation and behaviour, Eynan et al. (2002) reported that $72 \%$ of homeless people with psychotic disorders had attempted suicide, while for mood disorders this percentage was $42.5 \%$, it was $40 \%$ among drug users and $33 \%$ among those with post-traumatic stress disorder. Among homeless people with no psychiatric disorder, the percentage of those who had made suicide attempts was 11\% (Eynan et al. 2002). Meanwhile, Gelberg, Linn \& Leake (1988) reported that homeless adults in Los Angeles with a history of using mental health services had attempted to commit suicide about 6 times more often than those who had not used those services (34\% vs. 6\%). Among homeless substance abusers, a history of sexual abuse, including a history of sexual abuse in childhood (Afifi, Boman, Fleisher, \& Sareen, 2009; Benda, 2005) or physical abuse or current physical or sexual abuse (Benda, 2005) was associated with reports of suicidal thoughts (Rodell et al., 2003).

This paper aims to determine the relationship between suicide attempts and the number and characteristics of the SLE experienced by homeless people in Madrid, both specifically during childhood and adolescence and throughout their lives. This study also aims to identify the combination of SLE that predicts suicide attempts in that group to the greatest extent.

\section{Method}

\section{Sample}

The study was carried out with a representative sample of homeless people in the city of Madrid, consisting of 188 people over 18 years old, who had spent the night before the interview in a shelter for the homeless, on the street or other places not initially designed for sleeping (abandoned buildings, basements, subway stations, etc.).

The sample size was determined beforehand, based on the available data for the total number of homeless people in Madrid (Vázquez, Panadero, \& Zúñiga, 2017). To delimit the number of homeless people in Madrid (2,130 people), we used data provided by the City Council of Madrid regarding accommodation places for homeless people taken up in the winter of 2011-12 was used (761 permanent places in the municipal network of the Madrid City Council, 357 places in the so-called "cold campaign", and 412 places in the social initiative network: total 1,530 places) and data on homeless people sleeping on the streets obtained from a night count carried out in the city (600 people). A strategy for random sampling in the street and in all housing resources for homeless people in the city of Madrid was designed. From the lists of users provided by each of the assistance services, specific number of participants were selected in each facility proportionately and randomly, according to their capacity. The sample selection in the street was carried out randomly and proportionally, based on a list of homeless people sleeping on the streets provided by the street outreach teams of the Madrid City Council. The main characteristics of the sample are shown in Table 1. 
Table 1. Main sociodemographic and educational characteristics and time spent homeless of homeless people in Madrid.

\begin{tabular}{lrr}
\hline Characteristics & n & Percentage/mean \\
\hline Sex & & \\
Male & 158 & $84.0 \%$ \\
Female & 30 & $16.0 \%$ \\
\hline Age (Mean (SD)) & & 47.57 yr. $(12.17)$ \\
\hline Marital status & 100 & $53.2 \%$ \\
Single & 7 & $3.7 \%$ \\
Married & 58 & $30.9 \%$ \\
Legally separated or divorced & 19 & $10.1 \%$ \\
Separated de facto without legal procedures & 3 & $1.6 \%$ \\
Widow/er & 1 & $0.5 \%$ \\
Other & & \\
\hline Nationality & 53 & $28.2 \%$ \\
Foreigners & 133 & $70.7 \%$ \\
Spanish & & \\
\hline Completed education & 5 & $2.7 \%$ \\
None (illiterate) & 6 & $3.2 \%$ \\
None (literate) & 1 & $0.5 \%$ \\
Special education & 11 & $5.9 \%$ \\
Incomplete primary & 45 & $23.9 \%$ \\
Primary & 64 & $34.0 \%$ \\
Secondary/first cycle (until 14 years old) & 32 & $17.0 \%$ \\
Secondary/second cycle (until 18 years old) & 22 & $11.7 \%$ \\
University (intermediate degree and above) & & \\
\hline Slept in one of the following places last month & 49 & $26.1 \%$ \\
In the street & 13 & $6.9 \%$ \\
In an unsuitable place & 132 & $70.2 \%$ \\
In a shelter & 182 & 7.0 yr. $(8.45)$ \\
\hline Time homeless (Mean (SD)) & & \\
\hline & & \\
& & \\
\end{tabular}

As shown in Table 1, the vast majority of homeless people in Madrid were male, of Spanish origin, and their mean age was 48 years old. While more than half of the interviewees were single, $46.3 \%$ had been married at some point in their life, although very few were still married when the interview took place. $9.6 \%$ had not completed primary education, while $12 \%$ had completed some form of university education. The people interviewed had been homeless for a mean period of seven years $(\mathrm{SD}=8.45)$, and the vast majority reported having slept in a shelter during the month prior to the interview.

\section{Procedure}

After the objectives of the research and the treatment that the data would receive were explained to the participants, they were asked for their informed consent, and assured that their anonymity would be respected at all times.

In view of the results obtained in previous studies (Muñoz, Vázquez, \& Vázquez, 2004), we assumed that a relatively high number of respondents would have a low or very low level of education, and that the number of homeless people in Madrid of foreign origin - with potential difficulties with understanding the language - would be relatively high. As a result, a structured interview was used to gather information, which enabled us to circumvent the possible problems arising from the interviewees' difficulties with reading and/or understanding. The interviews lasted between 45 and 80 minutes. 


\section{Measures}

The structured interview included the question: "have you attempted suicide at some point in your life?" with possible response options of "yes" or "no". We defined a suicide attempt as an "incident accompanied by self-reported intent to die" (Goldman-Mellor et al., 2014; Guillén et al., 2015).

When gathering information on the stressful life events (SLE) suffered, the L-SVE was used to do so [Listado de Sucesos Vitales Estresantes para Colectivos en Exclusión Social /List of Stressful Life Events for People in Social Exclusion], created upon the review of previous measuring instruments (Brugha y Cragg, 1990) and work conducted with people in a situation of social difficulty or exclusion (Guillén, et al., 2015; Muñoz, Vázquez, Bermejo \& Vázquez, 1999; Vázquez, et al., 2015; Vázquez, et al., 2007, 2010). The L-SVE consists of 43 possible SLE: 21 SLE that could have occurred before age 18 (see Table 2) and 22 SLE that could have occurred throughout the interviewee's life (see Table 3). The participants had to respond if they had suffered each of the SLE or not (dichotomising answer).

\section{Data analysis}

The database was developed and processed using the SPSS statistical analysis and data management system (version 19.0 for Windows). When making comparisons between the two groups, the $\chi 2$ statistic (Chi square) was used for nominal variables, and the non parametric Mann-Whitney $U$ test was used for continuous variables, as the assumptions for the Student- $t$ test for independent samples were not reached. For stressful life events, the risk of each event was computed between attempters and non-attempters. In univariate analyses, we computed the odds ratios with $95 \%$ confidence intervals by standard methods (Rudas, 1998).

A discriminant analysis (stepwise inclusion method) was subsequently carried out to identify the variables that discriminated between homeless people who had attempted suicide and those who had not.

\section{Results}

Among the homeless people interviewed in Madrid, 30.3\% (57) answered affirmatively to the question 'Have you attempted suicide at some point in your life?' $56.1 \%$ of these had attempted suicide on more than one occasion. Among the homeless people who had attempted suicide (the attempters), the first suicide attempt took place at a mean age of 35.1 years old (SD $=12.01)$. In $57.9 \%$ (33) of the cases, the first attempt occurred when the person was already homeless. No statistically significant differences were observed between the group of attempters and the group of non-attempters based on sociodemographic characteristics such as gender $(\chi 2(1)=0.001 ; p=.971)$, age $(t(180)=1.001 ; p=.318)$ or nationality $(\chi 2(1)=0.706$; $p=.401)$. Also, no statistically significant differences were observed between those who had attempted suicide just once in their life and those who had attempted suicide on more than one occasion based on gender $(\chi 2(1)=0.017 ; p=.897)$, age $(t(46)=0.556 ; p=.581)$ or nationality $(\chi 2(1)=0.696 ; p=.404)$.

The differences between attempters and non-attempters in terms of suffering from SLE are shown in Tables 2, 3 and 4. 
Table 2. Differences in suffering from Stressful Life Events before the age of 18 between homeless people who had attempted suicide at some point in their lives, and those who had not

\begin{tabular}{|c|c|c|c|c|c|}
\hline Stressful life events (SLE) & $\begin{array}{l}\text { Attempters } \\
\quad(\mathrm{n}=57)\end{array}$ & $\begin{array}{c}\text { Non } \\
\text { attempters } \\
(\mathrm{n}=125)\end{array}$ & $\chi^{2}$ & $\begin{array}{l}\text { Odds } \\
\text { ratio }\end{array}$ & $95 \% \mathrm{CI}$ \\
\hline \multicolumn{6}{|l|}{ Before 18 years old } \\
\hline Major financial problems. & $21.0 \%(20)$ & $35.1 \%(26)$ & $4.107^{*}$ & 2.037 & $\begin{array}{r}1.017- \\
4.082 \\
\end{array}$ \\
\hline $\begin{array}{l}\text { Prolonged unemployment of a } \\
\text { member of their family. }\end{array}$ & $24.6 \%(14)$ & $14.5 \%(18)$ & 2.707 & & \\
\hline $\begin{array}{l}\text { A parent had a physically } \\
\text { incapacitating health problem }\end{array}$ & $12.5 \%(7)$ & $20.8 \%(26)$ & 1.787 & & \\
\hline $\begin{array}{l}\text { A parent had a serious mental health } \\
\text { problem }\end{array}$ & $10.7 \%(6)$ & $3.2 \%(4)$ & $4.184^{*}$ & 3.630 & $\begin{array}{r}.982- \\
13.418\end{array}$ \\
\hline $\begin{array}{l}\text { A parent had problems with alcohol } \\
\text { or drugs }\end{array}$ & $28.1 \%(29)$ & $23.4 \%(16)$ & 0.458 & & \\
\hline A parent left the family home & $29.8 \%(17)$ & $14.5 \%(18)$ & $5.867^{*}$ & 2.503 & $\begin{array}{r}1.175- \\
5.331\end{array}$ \\
\hline $\begin{array}{l}\text { Serious fights and arguments } \\
\text { between the parents }\end{array}$ & $36.8 \%(21)$ & $20.8 \%(26)$ & $5.260^{*}$ & 2.221 & $\begin{array}{r}1.114- \\
4.429 \\
\end{array}$ \\
\hline Problems of family violence & $40.4 \%(23)$ & $15.2 \%(19)$ & $13.950 * * *$ & 3.774 & $\begin{array}{r}1.837- \\
7.754 \\
\end{array}$ \\
\hline One of their parents was in prison & $12.3 \%(7)$ & $4.8 \%(6)$ & 3.244 & & \\
\hline $\begin{array}{l}\text { Serious conflicts between them and } \\
\text { someone in your family }\end{array}$ & $33.3 \%(19)$ & $16.1 \%(20)$ & $6.837 * *$ & 2.600 & $\begin{array}{r}1.253- \\
5.393\end{array}$ \\
\hline Frequent changes of residence & $10.5 \%(6)$ & $18.4 \%(23)$ & 1.812 & & \\
\hline Suffered abuse & $26.8 \%(15)$ & $15.2 \%(19)$ & 3.403 & & \\
\hline Suffered sexual violence & $10.7 \%(6)$ & $2.4 \%(3)$ & $5.658^{*}$ & 4.880 & $\begin{array}{r}1.174- \\
20.279 \\
\end{array}$ \\
\hline Expelled from home & $15.8 \%(9)$ & $5.6 \%(7)$ & $5.069^{*}$ & 3.161 & $\begin{array}{r}1.114- \\
8.971 \\
\end{array}$ \\
\hline He/she was abandoned & $10.9 \%(6)$ & $6.5 \%(8)$ & 1.050 & & \\
\hline Ran away from home & $37.5 \%(21)$ & $23.4 \%(29)$ & 3.830 & & \\
\hline Parents divorced or separated & $27.3 \%(15)$ & $15.3 \%(19)$ & 3.536 & & \\
\hline $\begin{array}{l}\text { Brought up by people other than } \\
\text { their parents }\end{array}$ & $35.1 \%(20)$ & $25.8 \%(32)$ & 1.643 & & \\
\hline Housing problems in childhood & $8.8 \%(5)$ & $6.4 \%(8)$ & .332 & & \\
\hline Dropped out of school & $39.3 \%(22)$ & $38.4 \%(48)$ & .013 & & \\
\hline Expelled from school & $19.3 \%(11)$ & $15.3 \%(19)$ & .446 & & \\
\hline
\end{tabular}

$* \mathrm{p} \leq .05 ; * * \mathrm{p} \leq .01 ; * * * \mathrm{p} \leq .001$ 
As can be seen in Table 2, the attempters had suffered situations of violence and abandonment during childhood and adolescence to a greater extent. In specific terms, the likelihood that the attempters had suffered experiences such as parents leaving the family home, serious fights and arguments between the parents and serious conflicts between the participant and someone in their family during childhood or adolescence was 2.2, 2.5 and 2.6 times greater, respectively, than for non-attempters. There was an even greater probability of having suffered from sexual violence (3.2 times higher), violence in the family (3.8 times higher), and being thrown out of their home (4.9 times higher). Only one of the events considered (suffering from major financial problems during childhood and/or adolescence) had happened to the nonattempters more frequently.

The total number of SLE experienced in childhood and adolescence by the attempters was significantly higher than among the non-attempters. The attempters had at that stage of their lives experienced a mean of 5.0 events $(S D=3.74)$, while among non-attempters this mean was $3.3(S D=2.74)$. As a normal distribution could not be assumed, proven with the ShapiroWilk test (Attempters $S W=0.914 ; p=.003$; Non-attempters $S W=0.900 ; p=.000$ ), a non parametric contrast test was applied, Mann-Whitney $U$ test, which exposed the existance of statistically significant differences between attempters and non-attempters in terms of SLE (Table 3). The mean ranks show that attempters had experienced a significantly higher number of SLE during chilhood and adolescense in comparison to non- attempters.

Table 3. Mann-Whitney U test results for Stressful Life Events experienced during childhood and adolescence and throughout life.

\begin{tabular}{lccccc}
\hline & \multicolumn{2}{c}{ Attempters } & \multicolumn{2}{c}{ Non-attempters } & \\
\hline & Mean Rank & $\begin{array}{c}\text { Sum of } \\
\text { Ranks }\end{array}$ & Mean Rank & $\begin{array}{c}\text { Sum of } \\
\text { Ranks }\end{array}$ & $\mathrm{Z}$ \\
\hline $\begin{array}{l}\text { Stressful life events (SLE) } \\
\text { during childhood and }\end{array}$ & 99.13 & 4956.50 & 77.53 & 9071.50 & $-2.664^{* *}$ \\
$\begin{array}{l}\text { adolescence } \\
\begin{array}{l}\text { Stressful life events (SLE) } \\
\text { throughout life }\end{array}\end{array}$ & 115.53 & 5430.00 & 64.24 & 7137.00 & $-6.470^{* *}$ \\
\hline
\end{tabular}

$* \mathrm{p}<0,05 ; * * \mathrm{p}<0,001$ (bilateral)

As is apparent in Table 4, the attempters had a probability two to three times greater of having suffered from: illness, injury or serious accident; major financial problems; having drunk too much at some point in their life; having suffered from physical violence (over 18 years old) and having lost their home due to eviction, demolition or other causes. The probability of having suffered from other events, including abuse by their spouse or partner (3.1 times higher), having consumed drugs in excess at some point in their life (3.8 times higher), the death of their spouse or partner (4.2 times higher), having been admitted to a psychiatric hospital (7.8 times higher) and above all, having had a serious mental health problem (19.7 times higher) was even higher. Meanwhile, more of the non-attempters reported having emigrated from their country of origin. As for the total number of SLE experienced, during their lives the attempters had suffered from a mean of 13.3 events $(S D=4.56)$, while among nonattempters, this mean was $9.7(S D=3.68)$. As a normal distribution could not be assumed, proven with the Shapiro-Wilk test (Attempters $S W=0,945 ; p=.040$; Non-attempters $S W=$ 0,$975 ; p=$.), a non parametric contrast test was applied, Mann-Whitney $U$ test, that also exposed statistically significant differences between attempters and non-attempters in terms of SLE (Table 3). The mean ranks reveal that attempters experience a significantly higher number of SVE en comparison with non- attempters. 
Table 4. Differences in experiencing Stressful Life Events at some point in their lives between homeless people who had attempted suicide and those who had not

\begin{tabular}{|c|c|c|c|c|c|}
\hline Stressful life events (SLE) & $\begin{array}{l}\text { Attempters } \\
\quad(\mathrm{n}=57)\end{array}$ & $\begin{array}{c}\text { Non } \\
\text { Attempter } \\
\mathbf{s}(\mathrm{n}=125)\end{array}$ & $\chi^{2}$ & $\begin{array}{l}\text { Odds } \\
\text { ratio }\end{array}$ & $95 \% \mathrm{CI}$ \\
\hline Death of the father & $59.3 \%(32)$ & $73.0 \%(89)$ & 3.266 & & \\
\hline Death of the mother & $43.4 \%(23)$ & $54.8 \%(68)$ & 1.946 & & \\
\hline Death of the spouse or partner & $22.8 \%(13)$ & $6.5 \%(8)$ & $10.045^{* *}$ & 4.247 & $\begin{array}{l}1.648- \\
10.947\end{array}$ \\
\hline Death of a child & $7.0 \%(4)$ & $4.0 \%(5)$ & 0.737 & & \\
\hline $\begin{array}{l}\text { Suffered from a serious illness, injury } \\
\text { or accident }\end{array}$ & $63.2 \%(36)$ & $40.8 \%(51)$ & $7.843^{*}$ & 2.487 & $\begin{array}{r}1.304- \\
4.744 \\
\end{array}$ \\
\hline Separation or divorce from the spouse & $61.4 \%(35)$ & $53.6 \%(67)$ & .968 & & \\
\hline $\begin{array}{l}\text { Suffered from serious unemployment } \\
\text { problems }\end{array}$ & $70.2 \%(40)$ & $64.5 \%(80)$ & .560 & & \\
\hline $\begin{array}{llll}\begin{array}{l}\text { Suffered from major financial } \\
\text { problems }\end{array} & & \\
\end{array}$ & $80.7 \%(46)$ & $59.7 \%(74)$ & $7.725^{*}$ & 2.826 & $\begin{array}{r}1.336- \\
5.978 \\
\end{array}$ \\
\hline $\begin{array}{l}\text { Drunk too much at some point in their } \\
\text { life }\end{array}$ & $68.4 \%(39)$ & $47.6 \%(59)$ & $6.831 * *$ & 2.387 & $\begin{array}{r}1.233- \\
4.620 \\
\end{array}$ \\
\hline $\begin{array}{l}\text { Abused drugs at some point in their } \\
\text { life }\end{array}$ & $53.6 \%(30)$ & $23.4 \%(29)$ & $15.952 * * *$ & 3.780 & $\begin{array}{r}1.934- \\
7.386 \\
\end{array}$ \\
\hline Been in prison & $33.9 \%(19)$ & $26.4 \%(33)$ & 1.071 & & \\
\hline Admitted to a psychiatric hospital & $45.6 \%(26)$ & $9.7 \%(12)$ & $30.404 * * *$ & 7.828 & $\begin{array}{l}3.548- \\
17.270\end{array}$ \\
\hline $\begin{array}{l}\text { Done work that separated them from } \\
\text { their home }\end{array}$ & $41.1 \%(23)$ & $37.9 \%(47)$ & .163 & & \\
\hline $\begin{array}{l}\text { Lost their home due to eviction, } \\
\text { demolition or other causes }\end{array}$ & $40.4 \%(23)$ & $18.5 \%(23)$ & $9.793 * *$ & 2.971 & $\begin{array}{r}1.480- \\
5.961 \\
\end{array}$ \\
\hline Emigrated from their country of origin & $26.3 \%(15)$ & $48.0 \%(60)$ & $7.598 * *$ & .387 & $.195-.768$ \\
\hline Had a serious mental health problem & $50.0 \%(28)$ & $4.8 \%(6)$ & $51.355 * * *$ & 19.667 & $\begin{array}{r}7.431- \\
52.048\end{array}$ \\
\hline $\begin{array}{l}\text { Suffered from sexual assault (over } 18 \\
\text { years old) }\end{array}$ & $8.8 \%(5)$ & $3.2 \%(4)$ & 2.586 & & \\
\hline $\begin{array}{l}\text { Suffered abuse by their spouse or } \\
\text { partner }\end{array}$ & $28.1 \%(16)$ & $11.3 \%(14)$ & $7.952 * *$ & 3.066 & $\begin{array}{r}1.375- \\
6.837 \\
\end{array}$ \\
\hline $\begin{array}{l}\text { Suffered from physical violence (over } \\
18 \text { years old) }\end{array}$ & $33.9 \%(19)$ & $16.9 \%(21)$ & $6.445^{*}$ & 2.519 & $\begin{array}{r}1.219- \\
5.203 \\
\end{array}$ \\
\hline Reported to the police & $51.8 \%(29)$ & $41.6 \%(52)$ & 1.623 & & \\
\hline Arrested or detained for a crime & $52.6 \%(30)$ & $41.6 \%(52)$ & 1.924 & & \\
\hline Convicted of a crime & $35.1 \%(20)$ & $28.0 \%(35)$ & .933 & & \\
\hline
\end{tabular}

$* \mathrm{p} \leq .05 ; * * \mathrm{p} \leq .01 ; * * * \mathrm{p} \leq .001$ 
A discriminant analysis was subsequently carried out in order to identify variables that discriminated between attempters and non-attempters. To that end, the stepwise inclusion method was used with the Wilks Lambda procedure, with the dependent variable being defined as "Has tried to commit suicide", which took two values: 0 "Has not attempted suicide;" 1 "Has attempted suicide at some point". An analysis of the differences between the attempters and non-attempters guided the selection of independent variables, as this technique is quite sensitive to the relationship between sample size and the number of predictive variables.

Table 5 lists the standardised coefficients resulting from the discriminant analysis in which all the SLE for which statistically significant differences were identified between attempters and non-attempters were included as independent variables.

Table 5. Standardised coefficients of canonical discriminant functions

\begin{tabular}{lr}
\hline & Function \\
\hline Problems of family violence & .265 \\
\hline Death of the spouse or partner & .325 \\
\hline Abused drugs at some point in their life & .331 \\
\hline Lost his/her home due to eviction, demolition or other causes & .233 \\
\hline Emigrated from their country of origin & -.331 \\
\hline Suffered from a serious mental health & .740 \\
\hline Suffered from physical violence (over 18 years old) & .264 \\
\hline
\end{tabular}

The discriminant analysis indicated that a combination of seven independent variables ("Problems of family violence", "Death of the spouse or partner", "Abused drugs at some point in their life", "Lost his/her home due to eviction, demolition or other causes", "Emigrated from the country of origin", "Suffered from a serious mental health" and "Suffered from physical violence (over 18 years old)") provided the best possible discrimination between and nonattempters. The inclusion of other variables did not contribute significantly to the discrimination between the two groups, and as such they were not included in the discriminant function.

The results of the discriminant analysis revealed a statistically significant function that correlated with the variables of the group in 0.729 with a Chi-square $(\chi 2(19)=116.31)$ which was statistically significant. The centroids of the groups were -0.718 for the group consisting of non-attempters and 1.560 for the attempters group. The standardised coefficients shown in Table 4 show the sign and magnitude assigned to each of the three variables in the discriminant function, with a Wilks' lambda distribution of $0.469(p<.001)$. This function correctly classified $88.5 \%$ of all the original cases - a figure that exceeds the criterion of maximum randomness. $75.0 \%$ of the attempters and $94.7 \%$ of the non-attempters were assigned to the correct group. The criterion of accuracy of classification - a quarter higher than that obtained by randomness (Hair, Anderson, Tatham, \& Block, 1999) - was fulfilled for both.

The combination of drug abuse, having suffered the death of a spouse or partner, having suffered violence in the family during childhood and/or adolescence, having lost the home, not having emigrated, having suffered from serious mental health problems and having suffered from physical violence (after 18 years old) is therefore the combination that best explained membership of the group that included those who had attempted suicide. Similarly, the opposite circumstances predicted membership of the group of those who had not attempted suicide. 


\section{Conclusions and discussion}

A very high rate of suicide attempts was observed among homeless people in the city of Madrid, to the extent that $30 \%$ reported having attempted to commit suicide at least once during their lifetime. This figure is particularly worrying when it is compared with the percentage of people who have attempted suicide among the Spanish general population, which is around $1.5 \%$ (Gabilondo et al., 2007; Panadero \& Vázquez, 2016), or among people at risk of exclusion, which in Madrid stands at 18\% (Panadero \& Vázquez, 2016). As the level of difficulty or social exclusion increases, the percentage of people who claim to have attempted suicide increases considerably, to the point where among the homeless, one of the most socially excluded groups in developed countries, a third of this population have attempted suicide (Lamontagne et al., 1988; Eynan et al., 2002).

It is also a source of concern to note that among the homeless people in Madrid who reported attempting to commit suicide, the majority $(58 \%)$ had done so for the first time after becoming homeless, and more than half of those interviewed (56\%) had attempted suicide on more than one occasion. These data appear to confirm the existence of a close relationship between being homeless and engaging in suicidal behaviour - an issue that can be considered a public health problem.

The relationship between SLE and suicidal behaviour has been studied repeatedly, and there is ample evidence for its existence (Liu \& Miller, 2014). Meanwhile, as reported by various studies (Lantz, House, Mere, \& Williams, 2005; Vázquez et al., 2007; Vázquez et al., 2015), people living in poverty and/or social exclusion are at increased risk of suffering from SLE, of great intensity and in large quantities, during both childhood and adolescence and throughout their lives. In addition to hindering the social inclusion processes of the most disadvantaged groups (Vázquez \& Panadero, 2016), SLE seem to have a negative impact on vulnerability to engaging in suicidal behaviour. The results of this study seem to point in this direction: although homeless people in general have experienced many SLE both during their childhood and adolescence as well as in their adult life, these appear to have accumulated more significantly among those who had engaged in suicidal behaviour. In line with the observations in various studies (Beautrais et al., 1997; Cooper et al., 2002; Kaslow et al., 2005; Osvath et al., 2004; Pompili et al., 2011), among homeless people in Madrid, suffering from many SLE seems to be an important vulnerability factor for subsequent suicidal behaviour, especially when these events occur during the early years of life and are related to the family environment (Vázquez et al., 2010). Indeed, among homeless people in Madrid, the total number of SLE experienced in childhood and adolescence by those who had attempted suicide was significantly greater than those suffered by non-attempters. According to Van Heeringen and Mann (2014), early-life adversity and epigenetic mechanisms could affect brain circuitry and neurochemistry abnormalities, which could then influence the appearance of impaired cognitive control of mood, pessimism, reactive aggressive traits, impaired problem solving, over -reactivity to negative social signs, excessive emotional pain, and suicidal ideation, leading to suicidal behaviour.

In addition to the accumulation of SLE, this study highlights the relationship between suicidal behaviour and some specific events. The attempters were more likely to have lived during their childhood and adolescence in a more dysfunctional family environment (serious fights and arguments between the parents, one of their parents leaving the family home, mental health problems for one of their parents, frequent changes of the place of residence) and to have suffered from sexual and physical violence in the family environment. Both a history of physical and/or sexual abuse during childhood (Beautrais et al., 1996; Brown et al., 1999; Pompili et al., 2011; Vázquez et al., 2010) and impaired or neglectful parenting (Brent et al., 
1993; Beautrais et al., 1996; Johnson et al., 2002) also seem to be especially common SLE among homeless people in Madrid, and are associated with suicidal behaviour in adult life.

Homeless people in Madrid have also suffered from a large number of SLE during adulthood, and this was particularly common among the attempters, who were more likely to have suffered physical and mental health problems (illness, injury or serious accidents, serious health problems, admission to a psychiatric hospital, drug use, etc.), physical violence, illtreatment by their partner, death of their spouse or partner, loss of their home and major financial problems. We also found a higher probability among homeless people in Madrid that non-attempters had been involved in migratory processes. Accordingly, Navarro-Lashayas \& Eiroa-Orosa (2017) report that homeless immigrants in Bilbao (Spain) are subject to multiple SLE, and reported a suicide attempt rate of $13.1 \%$. This percentage, despite tripling that of the Spanish general population (1.5\%) (Gabilondo et al., 2017), is substantially lower than the percentage of adult homeless people who have attempted to commit suicide reported in other studies (Eynan et al., 2002; Gelberg, et al., 1988; Lamontagne, et al., 1988; Smith et al., 1993). Meanwhile, Spallek et al. (2015) found that the majority of immigrant groups in Europe did not present a higher risk of suicide than the local-born population, and some groups were even at substantially lower risk.

Lastly, the combination of having suffered from family violence in childhood and/or adolescence, physical violence (after age 18), excessive drug use at some point in life, serious mental health problems, the death of the spouse or partner, losing their home and not having emigrated was the combination that best predicted homeless people in Madrid having attempted suicide. These data are quite similar to those observed by Vázquez et al. (2010) for a sample of Spanish and Latin American students, in which the best predictor of suicidal behaviour was the combination of psychoactive substance abuse, health problems (physical and mental), physical or sexual assault (in childhood and in adult life), family problems and early abandonment.

In line with findings in other groups (Guillén et al., 2015; Vázquez et al., 2010), the results of this study emphasise the importance of experiences of violence, both in childhood and during adulthood, as vulnerability factors for suicidal behaviour, as well as other experiences of material and social losses. Also, an excessive intake of psychoactive substances and conditions of serious mental health problems seem to work as influential vulnerability factors in regard to attempting suicide. In this sense, Serafini et el. (2012) points out that use of substance such as cannabis, vastly consumed together with alcohol in homeless people in Madrid (Panadero, Vázquez, \& Martín, 2017), was a relevant risk factor associate with suicidal attemps in psychotic and non-psychotic samples.

Our study has several limitations. The level of analysis is at a descriptive level, and it is a cross-sectional study design, so caution must be taken when attempting to establish causal relationships. In addition, information on suicide attempts was collected using a single question, and we relied on self-reports which were not confirmed by external sources. Also, the impossibility of knowing exactly the characteristics of the people who declined to participate in the study prevents determining the possible existence of some bias in the sample. Also, it should be noted that the study is limited to Madrid, Spain, which makes it difficult to generalize the results to other contexts.

In accordance with the Stress-Diathesis Model of Suicidal Behaviour (Van Heeringen, 2012), reducing the impact of SLE, especially during the earliest stages of life, can influence a decrease in suicide attempts among people with a trait-like diathesis or susceptibility to suicidal behaviour. Given that people in situations of difficulty or social exclusion are exposed to quantitatively very numerous and qualitatively very serious experiences of SLE and occur at young ages, it is important to pay special attention to the development of protocols of early-on 
assessment of suicidal behaviours aimed at these groups. In the case of homeless people in Madrid, the suicide attempts rates reaches alarming dimensions, underlining the relevance of implementing programs for the prevention of suicide in this group. To do so, it would be important to offer training aimed at the detection and prevention of suicidal behaviours to the professionals working with homeless people, as well as designing protocols for the early assessmet of suicidal behaviour for their implementation in both assistance serives and by street outreach teams. Furthermore, for the prevention of suicidal behaviour among homeless people it would be worthy to enhance the functions of psychologists in the care services, as well as to reduce the multiple barriers homeless people encounter to access general care services in mental health, which would allow them to benefit from effective and sustained psychological treatments over time.

\section{Acknowledgments}

This research was supported by the "Agencia Estatal de Investigación" of the "Ministerio de Economía, Industria y Competitividad" of Spain (Ref. FEM2016-75317-R).

\section{References}

Afifi, T.O., Boman, J., Fleisher, W., \& Sareen, J. (2009). The relationship between child abuse, parental divorce, and lifetime mental disorders and suicidality in a nationally representative adult sample. Child abuse \& neglect, 33(3), 139-147. DOI: 10.1016/j.chiabu.2008.12.009

Barak, Y., Cohen, A., \& Aizenberg, D. (2004). Suicide among the homeless: a 9-year case-series analysis. Crisis, 25, 2, 51-3. DOI: http://dx.doi.org/10.1027/0227-5910.25.2.51

Barrow, S. M., Herman, D. B., Cordova, P., \& Struening, E. L. (1999). Mortality among homeless shelter residents in New York City. American Journal of Public Health, 89(4), 529534. DOI: 10.2105/AJPH.89.4.529

Beautrais, A.L., Joyce P.R., \& Mulder, R.T. (1997). Precipitating factors and life events in serious suicide attempts among youths aged 13 to 24 years. Journal of the American Academy of Child and Adolescent Psychiatry, 36, 1543-1551. DOI: 10.1016/S0890-8567(09)66563-1

Beautrais, A.L., Joyce P.R., \& Mulder, R.T. (1996). Risk factors for serious suicide attempts among youths aged 13 through 24 years. Journal of the American Academy of Child and Adolescent Psychiatry, 35, 1174-1182.

Benda, B.B. (2005). Gender differences in predictors of suicidal thoughts and attempts among homeless veterans that abuse substances. Suicide and Life-Threatening Behavior, 35(1), 106-116. DOI: $10.1521 /$ suli.35.1.106.59262

Brent, D.A., Perper, J.A., Moritz, G., Baugher, M., Roth, C., Balach, L., \& Schweers, J. (1993). Stressful life events, psychopathology, and adolescent suicide: A case control study. Suicide and Life-Treatening Behaviour, 23, 179-187. DOI: 10.1111/j.1943278X.1993.tb00178.x

Brown, J., Cohen, P., Johnson, J.G., \& Smailes, E.M. (1999). Childhood abuse and neglect: Specificity of effects on adolescents and young adult depression and suicidality. Journal of the American Academy of Child and Adolescent Psychiatry, 38, 1490-1496. DOI:10.1097/00004583-199912000-00009 
Brugha, T. S., \& Cragg, D. (1990). The list of threatening experiences: the reliability and validity of a brief life events questionnaire. Acta Psychiatrica Scandinavica, 82(1), 77-81. DOI: $10.1111 / \mathrm{j} .1600-0447.1990 . t b 01360 . x$

Cheng, A.T., Chen, T.H., Chen, C.C., \& Jenkins, R. (2000). Psychosocial and psychiatric risk factors for suicide. Case-control psychological autopsy study. The British Journal of Psychiatry, 177, 360-365. DOI: 10.1192/bjp.177.4.360

Cooper, J., Appleby, L., \& Amos, T. (2002). Life events preceding suicide by young people. Social Psychiatry and Psychiatric Epidemiology, 37, 271-275. DOI: $10.1007 / \mathrm{s} 001270200019$

Dietz, T.L. (2010). Substance misuse, suicidal ideation, and suicide attempts among a national sample of homeless. Journal of Social Service Research, 37(1), 1-18. DOI: dx.doi.org/10.1080/01488376.2011.524511.

Eynan, R., Langley, J., Tolomiczenko, G., Rhodes, A. E., Links, P., Wasylenki, D., \& Goering, P. (2002). The association between homelessness and suicidal ideation and behaviors: Results of a cross-sectional survey. Suicide and Life-Threatening Behavior, 32(4), 418-427. DOI: $10.1521 /$ suli.32.4.418.22341

Gabilondo, A., Alonso, J., Pinto-Meza, A., Vilagut, G., Fernández, A., Serrano-Blanco, A., ... Haro, J. M. (2007). Prevalencia y factores de riesgo de las ideas, planes e intentos de suicidio en la población general española. Resultados del estudio ESEMeD [Prevalence and risk factors for suicide ideation, plans and attempts in the Spanish general population. results from the ESEMeD study]. Medicina Clínica, 129, 494-500. DOI: dx.doi.org/10.1157/13111370

Gelberg, L., Linn, L., \& Leake, B. D. (1988). Mental health, alcohol and drug use, and criminal history among homeless adults. The American Journal of Psychiatry, 145(2), 191. DOI: 10.1176/ajp.145.2.191

Goldman-Mellor, S.J., Caspi, A., Harrington, H., Hogan, S., Nada-Raja, S., Poulton, R., $\&$ Moffitt, T.E. (2014). Suicide attempt in young people: A signal for long-term health care and social needs. JAMA psychiatry, 71(2), 119-127. DOI: 10.1001/jamapsychiatry.2013.2803

Guillén, A.I, Panadero, S., Rivas, E., \& Vázquez, J.J. (2015). Suicide attempts and stressful life events among female victims of intimate partner violence living in poverty in Nicaragua. Scandinavian Journal of Psychology, 56, 349-356. Doi: 10.1111/sjop.12207.

Hair, J.F., Anderson, R.E., Tatham, R.L., \& Black, W. (1999). Multivariate data analysis. New York: Prentice Hall.

Heikkinen, A., Isometsä, E., Henriksson, M., Marttunen, M., Aro, H., \& Lönnqvist, J. (1997). Psychosocial factors and completed suicide in personality disorders. Acta Psychiatrica Scandinavica, 95, 49-57. DOI: 10.1111/j.1600-0447.1997.tb00373.x

Hwang, S.W. (2000). Mortality among men using homeless shelters in Toronto, Ontario. Jama, 283(16), 2152-2157. DOI: 10.1001/jama.283.16.2152

Johnson, J.G., Cohen, P., Gould, M.S., Kasen, S., Brown, J., \& Brook, J.S. (2002). Childhood adversities, interpersonal difficulties, and risk for suicide attempts during late adolescence and early adulthood. Archives of General Psychiatry, 59, 741-749.

Kaslow, N.J., Sherry, A., Bethea, K., Wyckoff, S., Compton, M.T., Bender Grall, M., Scholl, L., Price, A.W., Kellermann, A., Thompson, N., \& Parker, R. (2005). Social risk and protective factors for suicide attempts in low income African American men and women. Suicide Life-Threatening Behavior. 35(4), 400-12. DOI: 10.1521/suli.2005.35.4.400 
Lamontagne, Y., Garceau-Durand, Y., Elie, R., \& Blais, S. (1988). The young homeless of Montreal: A longitudinal study. Canadian journal of psychiatry, 33(8), 716-722.

Lantz, P.M., House, J.S., Mero, R.P., \& Williams, D.R. (2005). Stress, life events, and socioeconomic disparities in health: Results from the American's Changing Lives Study. Journal of Health and Social Behaviour, 46, 274-88.

Leonori, L., Muñoz, M., Vázquez, C., Vázquez, J.J., Bravo, M., Nuche, M., Brandt, P., Bento A., \& Horenbek, B. (2000). The mental health and social exclusion European network: A research activity report on European homeless citizens. European Psychologist, 5(3), $245-$ 251. Doi: 10.1027//1016-9040.5.3.245.

Liu, R.T. \& Miller, I. (2014). Life events and suicidal ideation and behavior: A systematic review. Clinical Psychology Review, 34, 181-192. DOI: doi.org/10.1016/j.cpr.2014.01.006.

Lopez-Castroman J., Olié E., \& Courtet P. (2014) Stress and Vulnerability: A Developing Model for Suicidal Risk. In K. Cannon \& T. Hudzik (eds.), Suicide: Phenomenology and Neurobiology (pp. 87-100). Springer: Cham.

Muñoz, M; Vázquez, C., \& Vázquez, J.J. (2004). A comparison between homeless, domiciled and vulnerable populations in Madrid. Population, 59 (1), 129-141.

Muñoz, M; Vázquez, C; Bermejo, M. \& Vázquez, J.J. (1999). Stressful life events among homeless people: Quantity, types, timing and perceived causality. Journal of Community Psychology, 27(1), 73-87. DOI: 10.1002/(SICI)1520-6629(199901)27:1<73::AIDJCOP5>3.0.CO;2-\#.

Navarro-Lashayas, M.A., \& Eiroa-Orosa, F.J. (2017). Substance use and psychological distress is related with accommodation status among homeless immigrants. American Journal of Orthopsychiatry, 87(1), 23-33. DOI: dx.doi.org/10.1037/ort0000213

Nusselder, W.J., Slockers, M.T., Krol, T., Slockers, C.T., Looman, C.W.N., \& van Beeck, F. (2013) Mortality and life expectancy in homeless men and women in Rotterdam: 2001-2010. Plos One, 8, 10, e73979-e73979. DOI: doi.org/10.1371/journal.pone.0073979

Osvath, P., Vörös, V., \& Fekete, S. (2004). Life events and psychopathology in a group of suicide attempters. Psychopathology, 37, 36-40. DOI: 10.1159/000077018

Panadero, S. \& Vázquez, J.J. (2016). En las fronteras de la ciudadanía. Situación de las personas sin hogar y en riesgo de exclusión social en Madrid. Alcalá de Henares: Universidad de Alcalá.

Panadero, S., Vázquez, J.J., \& Martín, R.M. (2017). Alcohol, poverty and social exclusion: Alcohol consumption among the homeless and those at risk of social exclusion in Madrid. Adicciones, 29(1), 33-36. DOI: 10.20882/adicciones.830.

Paykel, E.S., Prusoff, B.A., \& Myers, J.K. (1975). Suicide attempts and recent life events. Archives of General Psychiatry, 37, 327-333. DOI: 10.1001/archpsyc.1975.01760210061003

Pompili, M., Innamorati, M., Szanto, K., Di Vittorio, C., Conwell, Y., Lester, D., \& Amore, M. (2011). Life events as precipitants of suicide attempts among first-time suicide attempters, repeaters, and non-attempters. Psychiatry Research, 186, 300-305. DOI: 10.1016/j.psychres.2010.09.003. 
Rodell, D.E., Benda, B.B., \& Rodell, L. (2003). Suicidal thoughts among homeless alcohol and other drug abusers. Alcoholism Treatment Quarterly, 21(2), 57-74. DOI: dx.doi.org/10.1300/J020v21n02_04

Rudas, T. (1998). Odds ratios in the analysis of contingency tables. London: SAGE Publications.

Serafini, G., Pompili, M., Innamorati, M., Rihmer, Z., Sher, L., \& Girardi, P. (2012). Can cannabis increase the suicide risk in psychosis? A critical review. Current Pharmaceutical Design, 18(32), 5165-5187. DOI : 10.2174/138161212802884663.

Smith, E. M., North, C. S., \& Spitznagel, E. L. (1993). Alcohol, drugs, and psychiatric comorbidity among homeless women: an epidemiologic study. The Journal of clinical psychiatry, 54(3), 82-87.

Spallek, J., Reeske, A., Norredam, M., Nielsen, S., Lehnhardt, J., et al. (2015). Suicide among immigrants in Europe. A systematic literature review. European Journal of Public Health, 25 (1), 63-71.

Van Heeringen, K. (2012). Stress-diathesis model of suicidal behavior. In Y. Dwivedi (Ed.) The neurobiological basis of suicide. CRC Press: Boca Ratón FL. (pp 113-123)

Van Heeringen, K., \& Mann, J.J. (2014). The neurobiology of suicide. The Lancet Psychiatry, 1(1), 63-72. DOI: doi.org/10.1016/S2215-0366(14)70220-2

Vázquez, J.J. \& Panadero, S. (2016). Chronicity and pseudo inheritance of social exclusion: Differences according to the poverty of the family of origin among trash pickers in León (Nicaragua). Human Rights Quarterly, 38(2), 379-390. Doi: 10.1353/hrq.2016.0037.

Vázquez, J.J., Panadero, S., \& Martín, R.M. (2015). Regional and national differences in stressful life events: The role of cultural factors, economic development, and gender. American Journal of Orthopsychiatry, 85(4), 392-396. Doi: dx.doi.org/10.1037/ort0000029.

Vázquez, J.J., Panadero, S., \& Rincón, P. (2007). Stressful life events in countries of differing economic development: Nicaragua, Chile, and Spain. Psychological Reports, 101, 193-201. Doi: 10.2466/PR0.101.1.193-201.

Vázquez, J.J., Panadero, S., \& Rincón, P. (2010). Stressful life events and suicidal behaviour in countries with different development levels: Nicaragua, El Salvador, Chile and Spain. Journal of Community and Applied Social Psychology, 20(4), 288-298. Doi: 10.1002/casp.1036.

Vázquez, J.J., Panadero, S., \& Zúñiga, C. (2017). Content and uniformity of stereotypes and meta-stereotypes of homeless people in Madrid (Spain). Journal of Community Psychology, 45(1), 128-137. DOI: 10.1002/jcop.21836 